\title{
Inhibitory effect of silibinin on EGFR signal-induced renal cell carcinoma progression via suppression of the EGFR/MMP-9 signaling pathway
}

\author{
LIANG LIANG $^{1,2^{*}}$, LEI LI $^{1,2^{*}}$, JIN ZENG $^{1,2}$, YANG GAO $^{1,2}$, YU-LE CHEN $^{1,2}$, ZHI-QIANG WANG ${ }^{1,2}$, \\ XIN-YANG WANG ${ }^{1,2}$, LUKE S. CHANG ${ }^{1,2}$ and DALIN HE ${ }^{1,2}$ \\ ${ }^{1}$ Department of Urology, The First Affiliated Hospital of Medical College of Xi'an Jiaotong University, \\ and ${ }^{2}$ Oncology Research Laboratory, Key Laboratory of Environment and Genes \\ Related to Diseases, Ministry of Education, Xi'an, P.R. China
}

Received February 29, 2012; Accepted May 3, 2012

DOI: 10.3892/or.2012.1874

\begin{abstract}
The activation of epidermal growth factor (EGF) through its receptor, EGFR, is one of the major mechanisms that mediate renal cell carcinoma (RCC) metastasis. Silibinin, a natural flavonoid antioxidant with pleiotropic anticancer capability, has shown anti-metastatic effects in a variety of cancers. However, the mechanism by which silibinin inhibits EGFR signal-induced migration and invasion of RCC cells is not clear. Here, we evaluated the potential roles of EGFR signaling cascade that affects RCC progression, and also investigated the inhibitory effect of silibinin on the EGFR signal-induced migration and invasion abilities of RCC cells. Our data indicated that silibinin inhibited migration and invasion of RCC cells in a dosedependent manner via blocking the EGFR signal, especially in the EGFR highly expressing RCC cells. Silibinin inhibited phosphorylation of EGFR and its downstream molecules ERK1/2 but did not affect phosphorylation of other downstream molecules, STAT3 and Akt, in human RCC cell lines. Moreover, our data suggested that silibinin significantly reduced the MMP-9 expression and its activity that was promoted by the EGFR signal, and also suppressed MMP9-dependent migration and invasion abilities of RCC cells. Taken together, this study clearly demonstrated that silibinin inhibited EGFR induced migration and invasion of RCC cells via blockade of EGFR/MMP-9 signaling. Thus, we
\end{abstract}

Correspondence to: Dr Dalin He, Department of Urology, The First Affiliated Hospital of Medical College of Xi'an Jiaotong University, 277 Yanta West Road, Xi'an 710061, P.R. China

E-mail: dalinhexjtu@126.com

*Contributed equally

Abbreviations: EGFR, epidermal growth factor receptor; MMP-9, matrix metallopeptidase 9; SB, silibinin; RCC, renal cell carcinoma; ERK, extracellular signal-regulated kinase

Key words: EGFR, silibinin, MMP-9, renal cell carcinoma, invasion, migration suggest that silibinin could be used as a potential effective drug for the inhibition of RCC metastasis.

\section{Introduction}

Renal cell carcinoma (RCC) accounted for $90-95 \%$ of neoplasms arising from the kidney and $\sim 3.8 \%$ of adult malignancy in 2010 (1). Unfortunately, $\sim 25-30 \%$ of patients have metastatic disease at first diagnosis, and $>95 \%$ of these have multiple metastases (2). An aberrant activation of numerous signal pathways, including EGFR signal, has been recognized as a hallmark of cancer cell survival and progression (3). The studies also have revealed that overexpression of EGFR has been linked to RCC progression (4-6).

Traditional systematic therapies for metastatic RCC tumors include immunotherapy, chemotherapy, and targeted therapy $(7,8)$. However, low response rates have significantly retarded the efforts to improve the prognosis. There are still no effective methods for the treatment of metastatic RCC (9). Thus, searching for novel therapeutic methods or agents is needed for improving the efficacy against metastatic RCC.

Acumulated evidence shows that silibinin, a natural flavonoid antioxidant, isolated from milk thistle (Silybum marianum), exerted pleiotropic anticancer capabilities in different human malignant tumors including prostate, bladder, breast, colon, and oral cancer (10-13). Due to the high efficacy of this drug against cancer as well as its non-toxic characteristics, the use of this drug provide a strong rationale for cancer prevention and adjuvant therapy compare with traditional chemical treatment.

In our previous study, we found that silibinin inhibited cell proliferation in human RCC Caki-1 cells through decreasing EGFR signaling activity (3). In this study on metastasis, we selected three human RCC cell lines that have various levels of EGFR expression as the cell models to investigate the potential role of EGFR signaling cascade in RCC progression and possible inhibitory effect of silibinin on this process. Our results demonstrated that silibinin suppressed RCC cell progression via inhibiting the EGFR signal cascade, and resultant EGFR signal dependent MMP-9 activation in human RCC ACHN, 
OS-RC-2 and SW839 cell lines, suggesting that silibinin might be a new anti-EGFR drug for metastatic RCC treatment.

\section{Materials and methods}

Cell lines and chemicals. Human RCC cell lines ACHN, OS-RC-2 and SW839 purchased from American Type Culture Collection (Manassas, VA) were maintained in DMEM medium, supplemented with $10 \%$ fetal bovine serum (Gibco, NY), $1 \%$ glycine (Gibco) and $1 \%$ penicillin-streptomycin in humidified $5 \% \mathrm{CO}_{2}$ incubator (Thermon, USA). Silibinin was purchased from Sigma (S0417-1G). Stock solution (50 mM in DMSO) was added to the media to achieve the indicated concentration, and then incubated for $24 \mathrm{~h}$ for various tests. We obtained EGF from Sigma (E4127-1MG); EGFR antagonist PD168393 (cat-513033) and MMP-9 inhibitor (cat-444278) from Calbiochem; MMP-2 inhibitor from Santa Cruz Biotechnology (sc-204092); and U0126 from Cell Signaling Technology (cat-9903S).

Immunohistochemistry (IHC). Ten sets of surgical specimens (primary tumor, adjacent normal renal tissue, and metastatic lymph node) were stored in the Department of Urology (Xi'an Jiaotong University, Xi'an, China). Immunohistochemical analyses of paraffin sections were performed with anti-EGFR Ab (sc-03, diluted 1:100, Cell Signaling Technology). Briefly, tissues were deparaffinized, rehydrated, then subjected to $30 \mathrm{~min}$ of antigen retrieval in a microwave oven at $96^{\circ} \mathrm{C}$, followed by $15 \mathrm{~min}$ of endogenous enzyme block with $3 \%$ hydrogen peroxide solution, incubated with primary antibody at $4^{\circ} \mathrm{C}$ overnight, and $30 \mathrm{~min}$ of DakoCytomation EnVision-HRP reagent incubation for rabbit antibodies. Signals were detected by diaminobenzidine (DAB) buffer followed by hematoxylin counterstaining. In the negative control, sections were incubated with N-universal negative control antibody under identical conditions. Protein expression was quantified with Image-Pro Plus 5.0 (Media Cybernetics Inc., USA) in 10 random microscopic (400x) fields in each slice, and data are presented as the average staining intensity of different groups.

Western blot analysis. After silibinin treatments of RCC cells with of various concentrations, total cellular lysates were prepared in lysis buffer $(50 \mathrm{mM} / 1$ of Tris- $\mathrm{HCl} / \mathrm{pH} 7.4,150$ $\mathrm{mM} / 1$ of $\mathrm{NaCl}, 0.1 \%$ SDS, $1 \mathrm{mM} / 1$ EDTA, $1 \mathrm{mM} / 1$ EGTA, $0.3 \mathrm{mM} / 1$ of PMSF, $0.2 \mathrm{mM} / 1$ of sodium orthovanadate, $1 \% \mathrm{NP} 40,10 \mathrm{mg} / \mathrm{ml}$ of leupeptin, and $10 \mathrm{mg} / \mathrm{ml}$ aprotinin). Total of $50 \mu \mathrm{g}$ protein were separated in $10 \%$ SDS-PAGE gel, and then transferred onto the PDVF membranes. The membrane was blocked with 5\% non-fat milk in PBS for 1 $\mathrm{h}$ at room temperature and incubated with primary antibody overnight at $4^{\circ} \mathrm{C}$. Anti-EGFR (sc-03, diluted 1:1000) and antiGAPDH (sc-32233, diluted 1:1000) antibody were obained from Santa Cruz Biotechnology (Santa Cruz, CA, USA), anti-phosphorylation of EGFR (Tyr1068) (cat-3777, diluted 1:1000), anti-ERK (cat-5013, diluted 1:1000), anti-pERK1/2 (Thr202/Tyr204) (cat-4370, diluted 1:1000), anti-AKT (cat9272, diluted 1:1000), anti-pAKT (Ser473) (cat-9271, diluted 1:1000), anti-Stat3 (cat-9132, diluted 1:1000) and anti-pStat3 (cat-9131, diluted 1:1000) antibodies were obtained from Cell Signaling Technology (MA, USA). The bands were visualized with the ECL detection system followed by exposure to
X-ray film. The relative photographic density was quantitated and analyzed using Glyko BandScan software (Glyko, USA).

Reverse transcription and real-time PCR. Total RNA was isolated with TRIzol reagents (Invitrogen, CA) and quantitated by absorbance at $260 \mathrm{~nm}$. Reverse transcription was performed with $2 \mu \mathrm{g}$ RNA using Rever-tAid ${ }^{\mathrm{TM}}$ First Strand cDNA synthesis kit (MBI Fermentas, Germany) according to the manufacturer's instructions. Expressions of MMP-9 and MMP-2 mRNAs were measured with quantitative PCR and GAPDH mRNA was used as internal control. The primer sequences are given below: MMP-9 (forward, 5'-TGTCGCTGTCAAAGTTC GAG-3'; reverse, 5'-TTCATCTTCCAAGGCCAATC-3'); MMP-2 (forward, 5'-GGACAGACGGAAGTTCTTGG-3'; reverse, 5'-CACTTTCCTGGGCAACAAAT-3'); GAPDH (forward, 5'-CATACCAGGAAATGAGCTTGACAA-3'; reverse, 5'-CTC CTCCACCTTTGAGGCTG-3') was used as an internal control. The experiment was performed in 3 individual trials in triplicate.

Cell migration and invasion assay. Cell migration and invasion assays were performed using 24-well transwell plates (Falcon cell culture inserts, $8-\mu \mathrm{m}$ pore size, $\mathrm{BD}, \mathrm{NJ}$ ) according to the manufacturer's instructions. Briefly, for the invasion assay, ACHN, OS-RC-2 and SW839 cells $\left(4 \times 10^{4}\right)$, pretreated with various concentrations of silibinin $(25,50$ and $75 \mu \mathrm{M})$, with or without EGF treatment $(1,10$ and $50 \mathrm{nM})$ for $24 \mathrm{~h}$, were seeded into the upper chamber that had been precoated for $6 \mathrm{~h}$ with $50 \mu \mathrm{l}$ Matrigel $(2 \mathrm{mg} / \mu \mathrm{l}, \mathrm{BD})$ in medium containing no serum. The lower chamber was filled with $600 \mu 110 \%$ FBS medium. After a 48-h incubation, the penetrated cell will be fixed with $75 \%$ ethanol, stained with $1 \%$ crystal violet solution (Fisher Scientific, PA, USA), cells number were counted under microscope. For the migration assay, pretreated cells $\left(2 \times 10^{4}\right)$ were seeded into the uncoated transwell upper chamber, followed by a 24-h incubation, and then the cells in the membrane were fixed and stained similar to the invasion assay. All the invasion and migration assays were performed at least 3 individual experiments in triplicate.

Cell viability assay. Cell viability test was performed with a tetrazolium based assay (MTT). Cells $\left(1 \times 10^{3}\right)$ were seeded in a 96-well plate with $50 \mu 1$ media in triplicate, then treated with indicated doses of silibinin $(0,25,50$ and $75 \mathrm{mM})$ for $48 \mathrm{~h}$. MTT solution (20 $\mu \mathrm{l})(5 \mathrm{mg} / \mathrm{ml}$, MTT, Sigma, USA) was added to each well and incubated for $2.5 \mathrm{~h}$, and then developed with $200 \mu \mathrm{l}$ DMSO/well. The absorbance (OD) was detected at the wavelength of $570 \mathrm{~nm}$ with microplate autoreader (Bio-Tek Instruments, VT).

Zymography assay. The activities of MMP-2 and MMP-9 were detected by gelatin zymography protease assays. After treatment with EGF (1,10 and $50 \mathrm{nM})$, ACHN, OS-RC-2, and SW839 cells $\left(5 \times 10^{4}\right)$ were seeded in the 6 -well cell culture plate, treated with various concentrations of silibinin $(0,25,50$ and $75 \mu \mathrm{M})$, EGFR-antagonist, ERK-antagonist, MMP-2 inhibitor or MMP-9 inhibitor, for $24 \mathrm{~h}$. The conditioned media were collected and loaded into $10 \%$ SDS-PAGE containing $1 \mathrm{mg} / \mathrm{ml}$ gelatin. After electrophoresis at $4^{\circ} \mathrm{C}$, the SDS-PAGE gel was washed with $2.5 \%$ Triton X-100 washing buffer (2.5\% Triton X-100, $40 \mathrm{mM}$ 
A
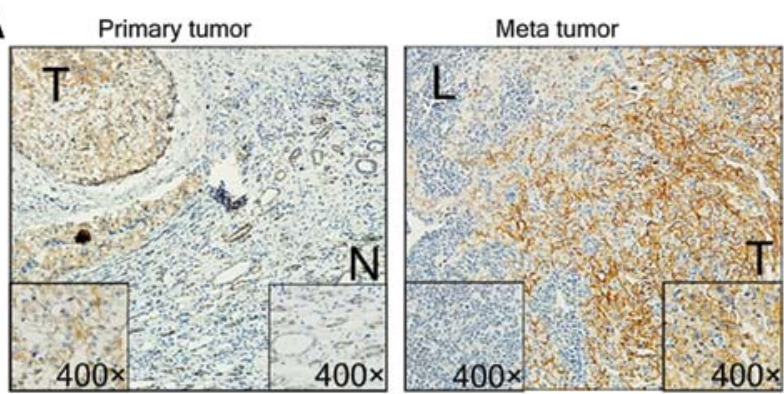

B

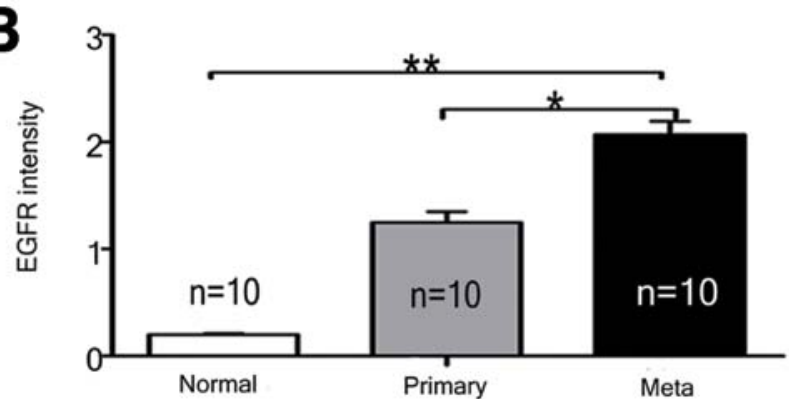

C
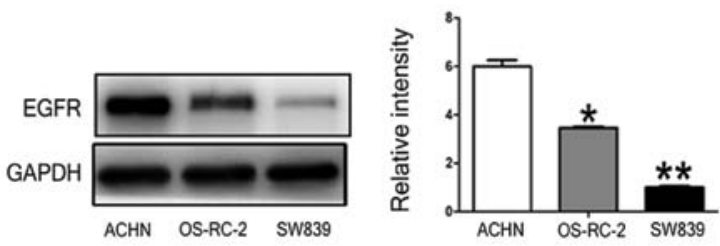

Figure 1. EGFR is overexpressed in metastatic RCC surgical specimens and cell lines. EGFR expression in ten sets of adjacent normal tissue, primary tumor, and metastatic tumor was detected by IHC staining (A). EGFR staining intensity was quantified (B) ( $\mathrm{p}<0.05,{ }^{* *} \mathrm{p}<0.01$ compared with normal tissue). EGFR expression was analyzed in RCC cell lines by western blotting (C). Protein loading was normalized and quantified against housekeeping gene GAPDH $\left({ }^{*} \mathrm{p}<0.05,{ }^{* *} \mathrm{p}<0.01\right.$ compared with ACHN cell).

Tris- $\mathrm{HCl} / \mathrm{pH} 8.0,10 \mathrm{mM} \mathrm{CaCl}_{2}, 1 \mathrm{mM} \mathrm{MgCl}$ ) for $1 \mathrm{~h}$, and then the gel was incubated in reaction buffer $(0.02 \%$ Brij35), $40 \mathrm{mM}$ Tris- $\mathrm{HCl} / \mathrm{pH} 8.0,10 \mathrm{mM} \mathrm{CaCl}_{2}, 1 \mathrm{mM} \mathrm{MgCl}_{2}$ ) for $24 \mathrm{~h}$ at $37^{\circ} \mathrm{C}$ and stained with Coomassie brilliant blue R-250 (Sigma, St. Louis, MO). The brightness of clear bands, where MMPs were located and gelatin was degraded, were analyzed by densitometry. The experiments were performed in triplicate.

Statistical analysis. All statistical analyses were carried out with SPSS 15.0 (SPSS Inc., Chicago, IL). Quantitative data are presented as mean $\pm \mathrm{SE}$, statistical significance among control group and various treated groups were accomplished by ANOVA, $p<0.05$ was considered as statistically significant. The data are representative of three independent experiments.

\section{Results}

Overexpression of EGFR in RCC cells. To evaluate the role of EGFR signaling in RCC progression, EGFR expression in RCC surgical tissue samples (ten sets of primary tumor, metastatic lymph nodes, and adjacent normal kidney tissue) were examined by IHC staining. Intensive positive signal was detected in the membrane and cytoplasm of primary (T) and metastatic tumor tissues (L), whereas weak signals were detected in the

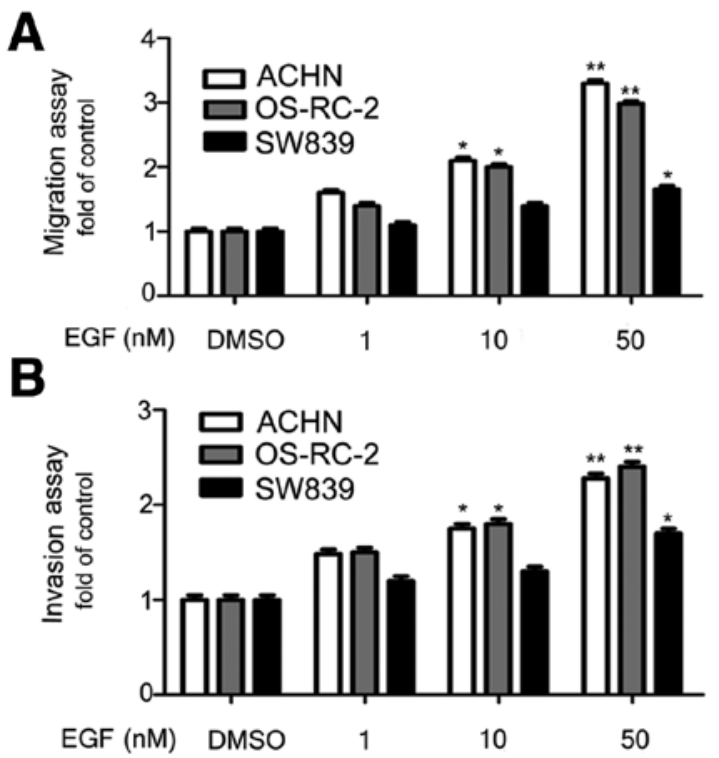

Figure 2. EGFR signal-induced RCC cell migration and invasion ability. ACHN, OS-RC-2, and SW839 cells were treated with varying concentrations of EGF (1, 10 and $50 \mathrm{nM}$ ), followed by migration (A) and invasion (B) assays for 24- and 48-h incubation. DMSO treatment was used as control. The data are presented as mean \pm SEM of three individual experiments in triplicate $\left({ }^{*} \mathrm{p}<0.05\right.$, p $<0.01$ compared with control group).

normal (N) kidney tissue (Fig. 1A). Significant higher expression of EGFR was observed in metastatic tumors compared to the primary tumors $(\mathrm{p}<0.05)$ and normal tissues $(\mathrm{p}<0.01)$. We further investigated EGFR expressions in several selected RCC cell lines and found that the ACHN cells derived from metastatic RCC displayed higher EGFR expression than the other two RCC cells (Fig. 1C), OS-RC-2 and SW839, which were derived from the primary RCC. These three cell lines were used in experiments in further in vitro studies.

EGFR signal promoted migration and invasion of ACHN, $O S-R C-2$, and SW839 cells. We investigated whether the EGFR signal can promote in vitro migration and invasion of RCC cells. We performed migration assays in transwell plates with addition of different doses of EGF. It was shown that the EGFR signal enhanced migration ability of ACHN and OS-RC-2 cells significantly and the highest effect was obtained at 10 and 50 nM EGF (Fig. 2A). Similar result was obtained in the invasion assay (Fig. 2B). We observed EGF effect on enhancing migration and invasion abilities of SW839 cells at $50 \mathrm{nM}$, but not at lower concentration, suggesting that the EGFR signal promote migration and invasion of RCC cells.

EGFR-dependent inhibitory effect of silibinin on RCC cell migration and invasion. We next tested the effect of silibinin on migration and invasion of ACHN, OS-RC-2 and SW839 cell lines. The MTT assay result indicated that silibinin did not result in cytotoxicity of cells at $25-75 \mu \mathrm{M}$ range (Fig. $3 \mathrm{~A})$. Therefore, we used this concentration range for further experiments. We found that the silibinin treatment (from 25 to $75 \mu \mathrm{M})$ significantly reduced migration and invasion of OS-RC-2 cell (20-60\% for migration and 30-60\% for invasion), and ACHN cell (30-60\% for migration and 40-65\% 


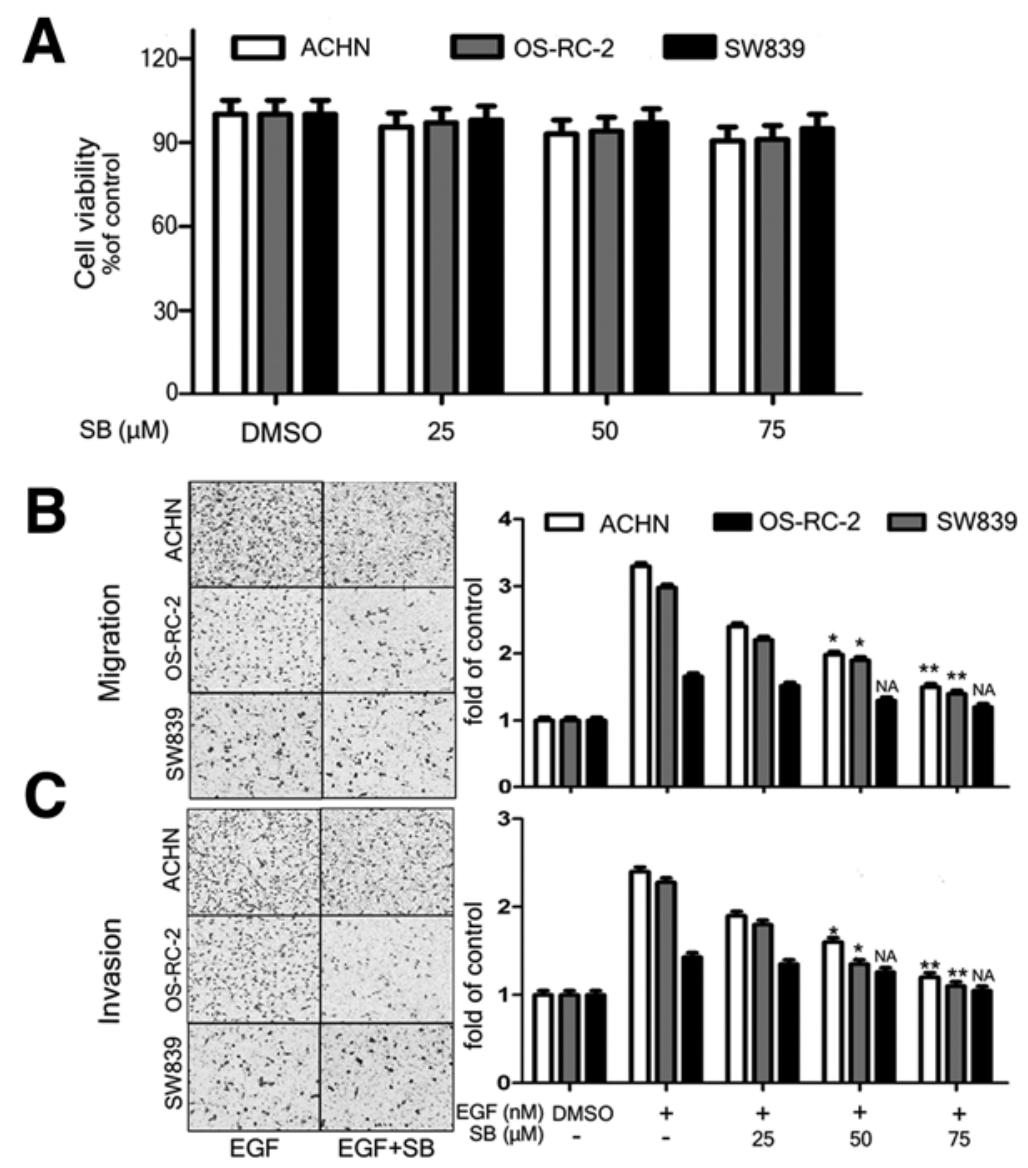

Figure 3. EGFR-dependent inhibitory effect of silibinin on RCC cell migration and invasion. ACHN, OS-RC-2, and SW839 cells were treated with varying concentrations of silibinin (25,50 and $75 \mu \mathrm{M})$ for $24 \mathrm{~h}$, followed by MTT cell viability assay (A). DMSO treatment was used as control. EGF-pretreated ACHN, OS-RC-2, and SW839 cells were treated with varying concentrations of silibinin $(25,50$ and $75 \mu \mathrm{M})$ for $24 \mathrm{~h}$, followed by cell migration (B) and invasion (C) assays. DMSO was used as the negative control, EGF only treatment was the positive control. The data are presented as mean \pm SEM of three independent experiments $\left({ }^{*}<<0.05\right.$, *** $\mathrm{p}<0.01$ compared with positive control group).

of invasion). However, no significant inhibitory was demonstrated in SW839 cells, which express low level of EGFR, even at the high concentration of silibinin (Fig. 3B and C). These results indicated that the dose-dependent inhibitory effects of silibinin on EGFR signal-induced cell migration and invasion occurs only in the RCC cells that express high level of EGFR. Therefore, we can conclude that the inhibitory effect of silibinin on migration and invasion abilities of RCC cells was via suppression of EGFR signal.

Decrease in phosphorylation of EGFR and ERK attribute to the inhibitory effect of silibinin. To further investigate whether the inhibitory effect of silibinin is via EGFR signal, we tested phosphorylated EGF level in RCC cells upon silibinin treatment. We treated ACHN, OS-RC-2 and SW839 cells with EGF $(1,10$ and $50 \mathrm{nM})$ and examined phosphorylation of EGFR. As shown in Fig, 4A, we observed EGF-dependent phosphorylation of EGFR. The phophorylation of EGFR further activated EGFR downstream signals such as ERK1/2, AKT, and STAT3 (Fig. 4B). So, we tested whether silibinin can inhibit the phosphorylation of EGFR and its downstream signals. It was found that silibinin significantly reduced phosphorylated EGFR and ERK1/2 levels in EGFR high expressing ACHN and OS-RC-2 cells $(p<0.05)$, but not in EGFR low expressing SW839 cells $(p>0.05)$, the inhibitory effect of silibinin on phosphorylated
EGFR level was comparable to the effect of known EGFR signal inhibitor PD168393 (Fig. 4B). However, silibinin did not affect phosphorylation of STAT3 and AKT in three cell lines tested (Fig. 4B).

Silibinin diminishes EGFR-mediated increase in MMP-9 expression and activity in EGFR high expressing RCC cells. Previous studies have demonstrated that MMP-9 and MMP-2 play important roles in mediating migration and invasion of variety of cancer cells (14). Here, we found that the EGFR signal significantly unregulated MMP-9 mRNA expression and activity, but did not affect MMP-2, expression and activity, in the three cell lines tested (Fig. 5A and B).

Interestingly, our data showed that silibinin abolished EGFR-induced MMP-9 activity similar to the effect shown by the EGFR inhibitor, PD168393, and the ERK inhibitor, U0126, in the EGFR high expressing ACHN and OS-RC-2 cells, not in the EGFR low expressing SW839 cells (Fig. 5C). These results suggest that silibinin blocked the EGFR and its downstream ERK signals, which in turn, inhibited expression and activity of MMP-9, especially in EGFR high expressing cells.

MMP-9 is the key molecule in exerting silibinin effect on inhibiting EGFR signal-induced migration and invasion of RCC cells. Since the EGFR-signal significantly increased MMP-9 mRNA 


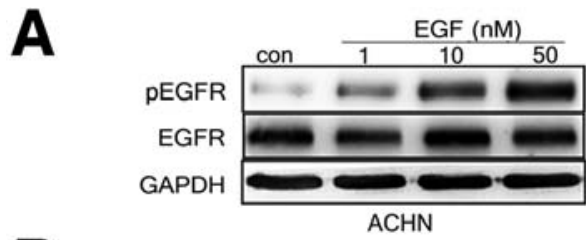

B

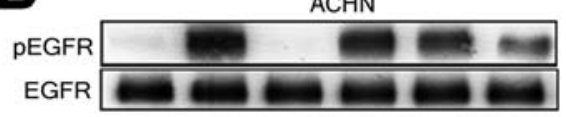

pERK $=\mathrm{s}-\mathrm{s}=\mathrm{E}$

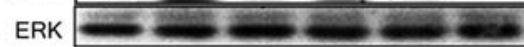

PAKT $\square-\cdots-$

$\mathrm{AKT}=-\cdots$

pSTAT3 $\square-\cdots$

STAT3

GAPDH -

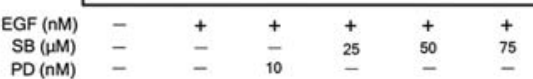

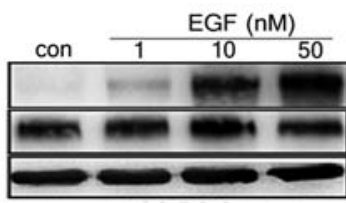

OS-RC-2

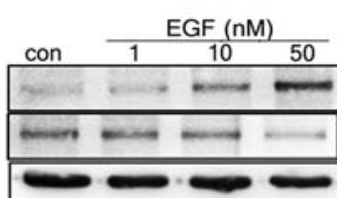

SW839
OS-RC-2
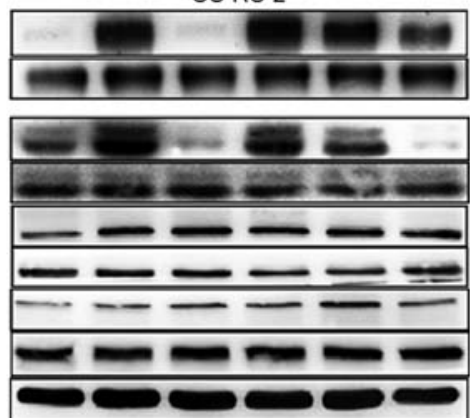

$\begin{array}{lllll}- & + & + & + & +\end{array}$
SW839
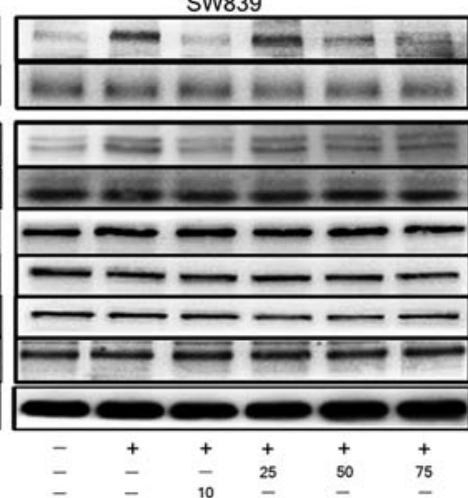

Figure 4. Silibinin significantly inhibits activation of EGFR/ERK signal pathway in EGFR high expressing RCC cells. Serum starved ACHN, OS-RC-2, and SW839 cells were treated with EGF $(1,10$ and $50 \mathrm{nM})$ for $30 \mathrm{~min}$, and then western blot analysis was performed using anti-phosphorylation and total EGFR antibodies (A). Before EGF treatment, cells were incubated with varying concentrations of silibinin $(0,25,50$ and $75 \mu \mathrm{M})$, or combination with $10 \mathrm{nM}$ PD168393, an antagonist of EGFR, then western blot analysis was peformed using anti-p-ERK/ERK, anti-pAKT/AKT and anti-pStat3/Stat3 antibody (B). GAPDH served as a loading control. The data are presented as three independent experiments.
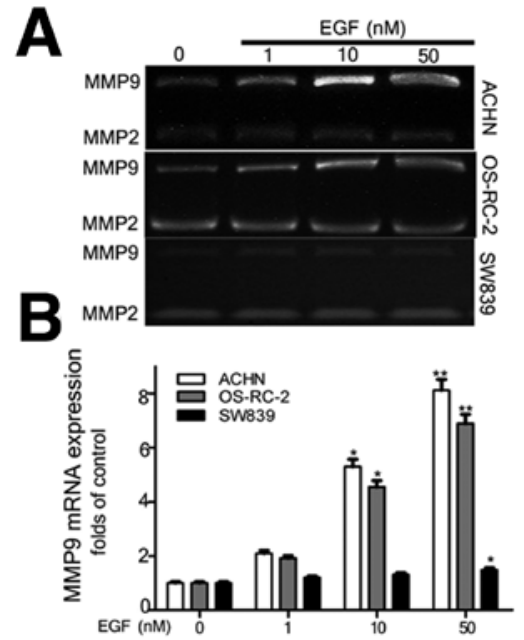
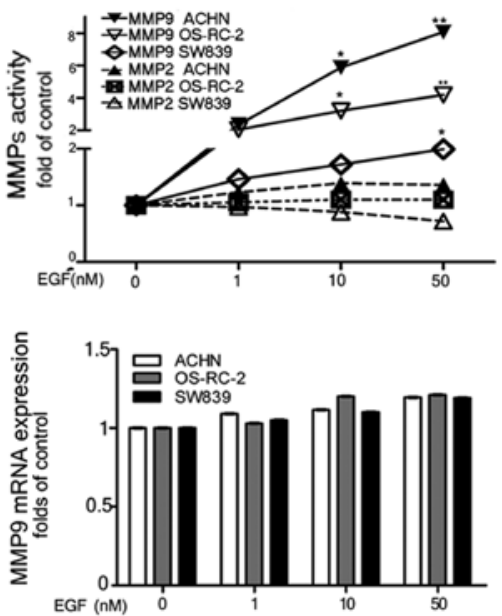

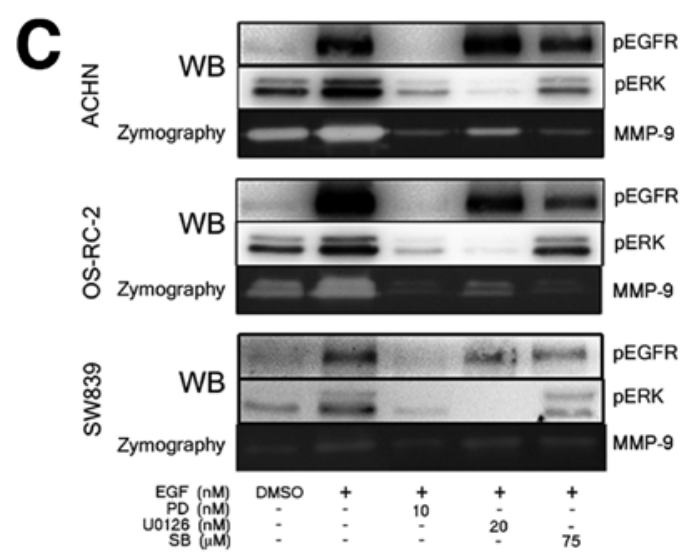

Figure 5. Silibinin diminishes EGFR signal induced MMP-9 via the blocking the activated EGFR/ERK signal. Serum starved ACHN, OS-RC-2 and SW839 cells were treated with varying various concentrations of EGF (1, 10 and $50 \mathrm{nM}$ ) for $24 \mathrm{~h}$, and then MMPs zymography and q-PCR assay for MMP-2 and MMP-9 activity (A) and mRNA expression (B). EGF-treated ACHN, OS-RC-2, and SW839 cells (at 50 nM) were incubated with either silibinin, PD168393, or U0126, for $1 \mathrm{~h}$, followed by western blotting (C) and MMP-9 zymography assay (C). DMSO was used as negative control, EGF only treated was the positive control. The data are presented as mean \pm SEM of three independent experiments $\left({ }^{*} \mathrm{p}<0.05,{ }^{* *} \mathrm{p}<0.01\right.$ compared with positive control group). 

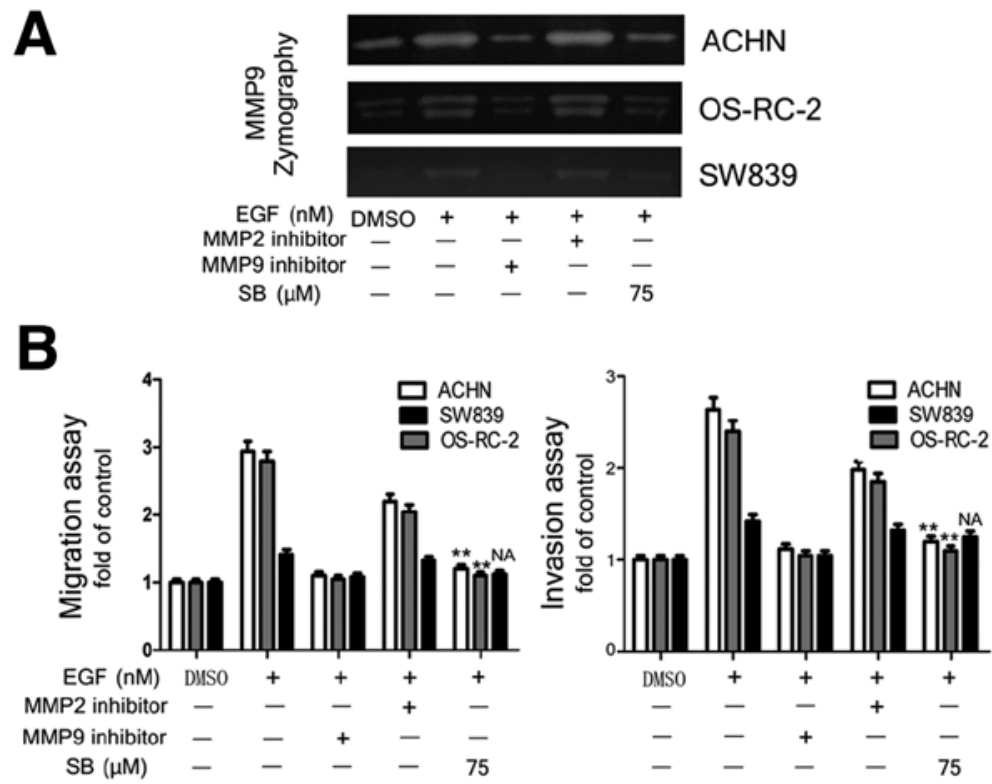

Figure 6. MMP-9 plays an essential role in inhibiting the effect of silibinin on the migration and invasion induced by EGFR signaling. EGF pretreated ACHN, OS-RC-2, and SW839 cells were incubated with either silibinin, MMP-9 inhibitor (10 nM), or MMP-2 inhibitor (10 nM) for $24 \mathrm{~h}$, followed with zymography (A), cell migration (B) and invasion assay (B). DMSO was used as negative control. EGF single treatment was used as the positive control. The data are presented as mean \pm SEM of three independent experiments $\left({ }^{*} \mathrm{p}<0.05,{ }^{* *} \mathrm{p}<0.01\right.$ compared with control group).

expression and activity, not MMP-2, we further investigated whether MMP-9 plays a role in RCC migration and invasion induced by EGFR signaling. The ACHN, OS-RC-2 and SW839 cell were stimulated with EGF, and then treated with inhibitors of MMP-2 and MMP-9, or silibinin for $24 \mathrm{~h}$, and the activities of MMP-2 and MMP-9 were tested by zymography. Silibinin and MMP-9 inhibitor both showed inhibition of EGFR signalinduced MMP-9 activity, cell migration and invasion abilities in EGFR high expressing ACHN and OS-RC-2 cells (Fig. 6A), but the MMP-2 inhibitor did not. These results confirmed that MMP-9 is the key molecule to mediate EGFR signal-induced RCC progression (Fig. 6B).

Collectively, it can be concluded that silibinin inhibited EGFR signal-induced invasion and migration of RCC cells via blocking of EGFR/MMP-9 signaling and it suggests the possibility of using silibinin as a new anti-EGFR drug to treat metastatic RCC.

\section{Discussion}

In the present study, we first demonstrated the effects of silibinin on progression of RCC cells induced by EGFR signal in vitro. Employing three different human RCC cell lines, ACHN, OS-RC-2 and SW839, with various levels of EGFR expression, we demonstrated that, silibinin, a natural flavonoid antioxidant isolated from milk thistle, could inhibit EGFR signaling-induced migration and invasion of RCC cells via suppressing EGFR/ MMP-9 signaling.

The potential agents for treatment of advanced RCC through targeting EGFR signaling have been studied $(15,16)$. The antibodies and small molecule inhibitors that targets EGFR pathway have entered clinical trials of RCC patients $(17,18)$.

Silibinin has been demonstrated to exert its anticancer effects by targeting EGFR. It was reported that silibinin inhibited ligand binding to EGFR and its internalization into the cytoplasm,
EGFR dimerization, ERK1/2 activation, as well as cell proliferation in advanced human prostate carcinoma cells (19). Moreover, silibinin was reported to be effective in decreasing TGF- $\alpha$ and impaired TGF- $\alpha$-EGFR-ERK1/2 signaling in both androgendependent (LNCaP) and -independent (DU145) advanced human prostate carcinoma cells (20). Consistent with these findings, we observed that silibinin inhibited EGFR and ERK1/2 phosphorylation, as well as cell proliferation of human RCC Cakil cells.

Besides its antiproliferative effect, silibinin also show antimetastatic effects on a variety of malignant tumors including prostate cancer, lung cancer, breast cancer, osteosarcoma and oral cancer $(11-13,21,22)$. Still little is known about suppression effect of silibinin on EGFR signal-induced RCC migration and invasion. Chang et al (23) reported that silibinin inhibited migration and invasion of RCC 786-O cells. However, RCC 786-O cell line was derived from a primary clear cell adenocarcinoma, which represents a cell type with less invasive potential. In this study, we employed three different human RCC cell lines derived from both primary and metastatic tumor that express various levels of EGFR. We demonstrated that, silibinin could inhibit the migration and invasion of RCC cells induced by EGFR signaling via blocking of EGFR/MMP-9 signaling. However, two other EGFR signaling downstream proteins, STAT3 and AKT, were not affected by silibinin, which is in agreement with previous results that silibinin inhibited cell migration and invasion through ERK1/2 signal, not AKT and STAT3 phosphorylation $(12,22,23)$.

Importantly, silibinin inhibited EGFR signal-induced cell migration and invasion in a dose-dependent manner, however, these effect, we believe, is EGFR expression-dependent based on our observation that the inhibitory effect of silibinin was observed in EGFR expressing cells (ACHN and OSORC-2), but not in EGFR low expressing cells (SW839), even at higher concentration of silibinin (75 $\mu \mathrm{M})$. Qi et al (24) also observed that EGF conferred silibinin-induced cytotoxicity in glioma cells 
that lack endogenous EGFR, which partly agree with our finding, although the potential mechanism is not clear. It seems that the migration and invasion of EGFR highly expressing cells depend on EGFR signaling, but probably the EGFR low expressing cells depend on other signal pathways to mediate their migration and invasion. The more precise role of EGFR signal in RCC cell survival and progression needs further study.

We found MMP-9 expression and activity, not MMP-2, were activated by the phosphorylation of EGFR/ERK signal by EGF stimulation in RCC cell lines. Silibinin, and an EGFR antagonist significantly suppressed EGFR signal-induced MMP-9 mRNA expression and activity, and subsequently decreased their invasion and migration. Qiu et al (25) showed EGF-stimulated MMP-9 expression and activity through PI3K and MAPK signal pathway. Tian et al (26) also found the induction of MMP-9 via EGF-induced pERK activation, and blocking of EGFR signal pathway with shRNA (27) or specific antagonist dramatically down-regulated MMP-9 expression (28). The evidence supports our findings that EGFR signal regulates the expression and activity of MMP-9.

Our study identified the vital role of EGFR/MMP-9 signal pathway in RCC progression, and provided first evidence that silibinin inhibited EGFR signal-induced migration and invasion in RCC cells via blocking of EGFR/MMP-9 signaling. The dramatic anti-metastatic effect of silibinin on RCC, especially in EGFR highly expressing cells, might suggest a potential effective therapy to cure advanced RCC.

\section{Acknowledgements}

We thank Karen Wolf for assistance with manuscript preparation (University of Rochester Medical Center, NY, USA); we also thank Dr Jiangzhou Yu and Dr Soo O.K. Lee, for their helpful review and discussion (University of Rochester Medical Center, NY, USA). This sudy was supported by National Natural Science Foundation of China (NSFC, no. 81101936).

\section{References}

1. Landis SH, Murray T, Bolden S and Wingo PA: Cancer statistics, 1999. CA Cancer J Clin 49: 8-31, 1999.

2. Maldazys JD and DeKernion JB: Prognostic factors in metastatic renal carcinoma. J Urol 136: 376-379, 1986.

3. Li L, Gao Y, Zhang L, Zeng J, He D and Sun Y: Silibinin inhibits cell growth and induces apoptosis by caspase activation, downregulating survivin and blocking EGFR-ERK activation in renal cell carcinoma. Cancer Lett 272: 61-69, 2008.

4. Dancey JE: Epidermal growth factor receptor and epidermal growth factor receptor therapies in renal cell carcinoma: do we need a better mouse trap? J Clin Oncol 22: 2975-2977, 2004.

5. Ishikawa J, Maeda S, Umezu K, Sugiyama T and Kamidono S: Amplification and overexpression of the epidermal growth factor receptor gene in human renal-cell carcinoma. Int J Cancer 45: 1018-1021, 1990.

6. Minner S, Rump D, Tennstedt P, et al: Epidermal growth factor receptor protein expression and genomic alterations in renal cell carcinoma. Cancer 118: 1268-1275, 2012.

7. Hutson TE: Targeted therapies. Oncologist 16 (Suppl 2): 14-22, 2011.

8. Itsumi M and Tatsugami K: Immunotherapy. Clin Dev Immunol 2010: 284581, 2010.

9. Yang JC, Sherry RM, Steinberg SM, et al: Low reponse rate randomized study of high-dose and low-dose interleukin-2 in patients with metastatic renal cancer. J Clin Oncol 21: 3127-3132, 2003.
10. Velmurugan B, Gangar SC, Kaur M, Tyagi A, Deep G and Agarwal R: Silibinin exerts sustained growth suppressive effect against human colon carcinoma SW480 xenograft by targeting multiple signaling molecules. Pharm Res 27: 2085-2097, 2010.

11. Wu KJ, Zeng J, Zhu GD, et al: Silibinin inhibits prostate cancer invasion, motility and migration by suppressing vimentin and MMP-2 expression. Acta Pharmacol Sin 30: 1162-1168, 2009.

12. Chen PN, Hsieh YS, Chiang CL, Chiou HL, Yang SF and Chu SC: Silibinin inhibits invasion of oral cancer cells by suppressing the MAPK pathway. J Dent Res 85: 220-225, 2006.

13. Singh RP, Raina K, Sharma G and Agarwal R: Silibinin inhibits established prostate tumor growth, progression, invasion, and metastasis and suppresses tumor angiogenesis and epithelialmesenchymal transition in transgenic adenocarcinoma of the mouse prostate model mice. Clin Cancer Res 14: 7773-7780, 2008.

14. Stamenkovic I: Matrix metalloproteinases in tumor invasion and metastasis. Semin Cancer Biol 10: 415-433, 2000.

15. Asakuma J, Sumitomo M, Asano T, Asano T and Hayakawa M: Modulation of tumor growth and tumor induced angiogenesis after epidermal growth factor receptor inhibition by ZD1839 in renal cell carcinoma. J Urol 171: 897-902, 2004.

16. Prewett M, Rothman M, Waksal H, Feldman M, Bander NH and Hicklin DJ: Mouse-human chimeric anti-epidermal growth factor receptor antibody C225 inhibits the growth of human renal cell carcinoma xenografts in nude mice. Clin Cancer Res 4 : 2957-2966, 1998.

17. Rowinsky EK, Schwartz GH, Gollob JA, et al: Safety, pharmacokinetics, and activity of ABX-EGF, a fully human anti-epidermal growth factor receptor monoclonal antibody in patients with metastatic renal cell cancer. J Clin Oncol 22: 3003-3015, 2004.

18. Motzer RJ, Amato R, Todd M, et al: Phase II trial of antiepidermal growth factor receptor antibody $\mathrm{C} 225$ in patients with advanced renal cell carcinoma. Invest New Drugs 21: 99-101, 2003.

19. Singh RP and Agarwal R: A cancer chemopreventive agent silibinin, targets mitogenic and survival signaling in prostate cancer. Mutat Res 555: 21-32, 2004

20. Tyagi A, Sharma Y, Agarwal C and Agarwal R: Silibinin impairs constitutively active TGFalpha-EGFR autocrine loop in advanced human prostate carcinoma cells. Pharm Res 25: 2143-2150, 2008.

21. Singh RP, Gu M and Agarwal R: Silibinin inhibits colorectal cancer growth by inhibiting tumor cell proliferation and angiogenesis. Cancer Res 68: 2043-2050, 2008.

22. Hsieh YS, Chu SC, Yang SF, Chen PN, Liu YC and Lu KH: Silibinin suppresses human osteosarcoma MG-63 cell invasion by inhibiting the ERK-dependent c-Jun/AP-1 induction of MMP-2. Carcinogenesis 28: 977-987, 2007.

23. Chang HR, Chen PN, Yang SF, et al: Silibinin inhibits the invasion and migration of renal carcinoma $786-\mathrm{O}$ cells in vitro, inhibits the growth of xenografts in vivo and enhances chemosensitivity to 5-fluorouracil and paclitaxel. Mol Carcinog 50: 811-823, 2011.

24 Qi L, Singh RP, Lu Y, et al: Epidermal growth factor receptor mediates silibinin-induced cytotoxicity in a rat glioma cell line. Cancer Biol Ther 2: 526-531, 2003.

25. Qiu Q, Yang M, Tsang BK and Gruslin A: EGF-induced trophoblast secretion of MMP-9 and TIMP-1 involves activation of both PI3K and MAPK signalling pathways. Reproduction 128: 355-363, 2004.

26. Tian YC, Chen YC, Chang CT, et al: Epidermal growth factor and transforming growth factor-beta1 enhance HK-2 cell migration through a synergistic increase of matrix metalloproteinase and sustained activation of ERK signaling pathway. Exp Cell Res 313: 2367-2377, 2007.

27. Kang CS, Pu PY, Li YH, et al: An in vitro study on the suppressive effect of glioma cell growth induced by plasmid-based small interference RNA (siRNA) targeting human epidermal growth factor receptor. J Neurooncol 74: 267-273, 2005.

28. Sumitomo M, Asano T, Asakuma J, Asano T, Horiguchi A and Hayakawa M: ZD1839 modulates paclitaxel response in renal cancer by blocking paclitaxel-induced activation of the epidermal growth factor receptor-extracellular signal-regulated kinase pathway. Clin Cancer Res 10: 794-801, 2004. 